\title{
Hyper-acute EEG alterations predict functional and morphological outcomes in thrombolysis-treated ischemic stroke: a wireless EEG study
}

\author{
Miloš Ajčević ${ }^{1}$ (1) Giovanni Furlanis ${ }^{2} \cdot$ Marcello Naccarato $^{2} \cdot$ Aleksandar Miladinović $^{1} \cdot$ Alex Buoite Stella $^{2}$. \\ Paola Caruso $^{2} \cdot$ Tommaso Cillotto $^{2} \cdot$ Agostino Accardo $^{1} \cdot$ Paolo Manganotti $^{2}$
}

Received: 29 April 2020 / Accepted: 20 October 2020 / Published online: 4 December 2020

(C) The Author(s) 2020

\begin{abstract}
Owing to the large inter-subject variability, early post-stroke prognosis is challenging, and objective biomarkers that can provide further prognostic information are still needed. The relation between quantitative EEG parameters in pre-thrombolysis hyperacute phase and outcomes has still to be investigated. Hence, possible correlations between early EEG biomarkers, measured on bedside wireless EEG, and short-term/long-term functional and morphological outcomes were investigated in thrombolysistreated strokes. EEG with a wireless device was performed in 20 patients with hyper-acute $(<4.5 \mathrm{~h}$ from onset) anterior ischemic stroke before reperfusion treatment. The correlations between outcome parameters (i.e., 7-day/12-month National Institutes of Health Stroke Scale NIHSS, 12-month modified Rankin Scale mRS, final infarct volume) and the pre-treatment EEG parameters were studied. Relative delta power and alpha power, delta/alpha (DAR), and (delta+theta)/(alpha+beta) (DTABR) ratios significantly correlated with NIHSS 7-day (rho $=0.80,-0.81,0.76,0.75$, respectively) and NIHSS 12 -month $(0.73,-0.78,0.74,0.73$, respectively), as well as with final infarct volume $(0.75,-0.70,0.78,0.62$, respectively). A good outcome in terms of $\mathrm{mRS} \leq 2$ at 12 months was associated with DAR parameter $(p=0.008)$. The neurophysiological biomarkers obtained by non-invasive and portable technique as wireless EEG in the early pre-treatment phase may contribute as objective parameters to the short/long-term outcome prediction pivotal to better establish the treatment strategies.
\end{abstract}

Keywords EEG $\cdot$ NIHSS $\cdot$ Hyperacute ischemic stroke $\cdot$ Biomedical signal processing $\cdot$ Outcome prediction

\section{Introduction}

Ischemic stroke is a neuroemergency condition in which reperfusion therapy in selected patients can restore cerebral blood flow and lead to improvement or resolution of neurological deficits [24]. Thrombolytic therapy delivered within $4.5 \mathrm{~h}$ from stroke onset significantly improves the overall odds of a good stroke outcome [27]. Recent studies highlighted the efficacy and safety of thrombolytic treatment in extended time

Miloš Ajčević

majcevic@units.it

1 Department of Engineering and Architecture, University of Trieste, Via A. Valerio, 10, 34127 Trieste, Italy

2 Clinical Unit of Neurology, Department of Medicine, Surgery and Health Sciences, Cattinara University Hospital ASUGI, University of Trieste, Strada di Fiume, 447, 34149 Trieste, Italy window, too (4.5-9 $\mathrm{h}$ from stroke onset or wake-up stroke) in patients selected by advanced neuroimaging $[7,8,15,20]$.

Early post-stroke prognosis is essential to better establish the treatment and rehabilitation strategies to improve recovery and minimize disability [6].

In the past, several independent early predictors of treatmentassociated stroke outcome like age, sex, mean arterial pressure, history of diabetes, baseline glucose levels, baseline National Institutes of Health Stroke Scale (NIHSS) score, neuroimaging findings, time to treatment and recanalization, current smoking, and atrial fibrillation were reported [11, 24, 28].

However, early prediction of post-stroke outcome is still challenging since there is large inter-subject variability [31]. For this reason, reliable, non-invasive, inexpensive biomarkers that provide further prognostic information are still needed.

There is growing evidence concerning neurovascular coupling in the acute phase of ischemic stroke, thus 
neurophysiological biomarkers seem increasingly prominent to predict the outcome [29].

EEG, as a non-invasive neurophysiological biomarker, provides a rapid evaluation of instantaneous brain function due to its high temporal resolution. Nowadays, thanks to the new wireless solutions, this diagnostic technique can also be applied bedside in emergency settings, as is acute stroke management [32].

EEG changes in sub-acute ischemic stroke and their predictive power have been studied previously [6, 12-14, 37]. Abnormal EEG and generalized, but not focal, slowing were associated with clinical deterioration with an increase of NIHSS $\geq 3$ from admission to discharge [37]. Furthermore, relative delta, alpha power, delta/alpha ratio (DAR), and the (delta + theta)/(alpha + beta) ratio (DTABR) EEG-related parameters have been associated with stroke functional and clinical outcome [12]. The relation between quantitative spectral EEG parameters in pre-thrombolysis hyper-acute phase and clinical and morphological outcome has not been studied yet. The thrombolysis currently represents the most common and efficacious treatment for intracranial vessel thrombosis. The study of the EEG alterations present before the treatment may contribute to the prediction of specific treatment outcome.

The aim of this study was to investigate the relation between early stroke-related EEG parameters, measured bedside with wireless EEG before the thrombolysis treatment, and short-term/long-term neurological disability measured with NIHSS and mRS in thrombolysis-treated ischemic stroke patients. In addition, we investigated the relation between quantitative EEG features with morphological outcome in terms of final ischemic lesion volume.

\section{Materials and methods}

\subsection{Study population and protocol}

The study included twenty patients $(8 \mathrm{M} / 12 \mathrm{~F}$, mean age 75.8 \pm 12.1 years) with first hyper-acute anterior ischemic stroke, who underwent EEG recording at bedside within $4.5 \mathrm{~h}$ since stroke onset before the reperfusion treatment. EEG recording was performed in the timespan between standard neuroimaging assessment (non-enhanced CT-NECT, Angio-CT, CT Perfusion-CTP) and the decision of possible reperfusion treatment. The wireless pre-set EEG system allowed hyper-acute bedside EEG assessment in emergency settings without compromising regular patient management and treatment. After the assessment, if the treatment inclusion criteria were fulfilled, patients underwent thrombolysis. Therefore, inclusion criteria were first-ever anterior circulation ischemic stroke undergoing systemic thrombolysis, in which EEG recording did not delay treatment decision and administration. Exclusion criteria were unknown stroke onset, wake-up stroke, stroke-mimic, previous stroke, hematic effusion, history of epileptic seizure, pre-morbid dementia, and use of medication such as neuroleptic or benzodiazepines were also exclusion criteria due to their effect on EEG assessment. The focus of the study was on thrombolysis-treated patients; therefore, patients who also received endovascular treatment were excluded.

The thrombolysis was performed with intravenous recombinant tissue plasminogen activator (rtPA) $(0.9 \mathrm{mg} / \mathrm{kg}$ of body weight, maximum of $90 \mathrm{mg}$, infused over $60 \mathrm{~min}$ with $10 \%$ of the total dose administered as an initial intravenous bolus over $1 \mathrm{~min})$.

During hospitalization, all patients received a standard clinical and diagnostic work-up, including a $22-36 \mathrm{~h}$ follow-up $\mathrm{CT}$ and neurological assessment.

The following data of included patients were collected: (1) demographic details (age, sex); (2) admission, 7-day, and 12month (after stroke event) NIHSS scores; (3) premorbid and 12-month mRS; (4) stroke risk factors (hypertension, diabetes mellitus, dyslipidemia, smoking, obesity, ischemic cardiopathy, atrial fibrillation); (5) NECT (ASPECTscore); (6) lesion side; (7) symptomatic intracerebral hemorrhage (sICH) according to the definition of ECASS (European-Australian Cooperative Acute Stroke Study 3) [17]; (8) stroke etiology by TOAST classification [1]; (9) stroke syndrome by Bamford classification; (10) time from symptom onset to EEG assessment.

This study was approved by the Local Ethics Committee CEUR (Comitato Etico Unico Regionale, FVG, Italy) with approval number 115/2018. The research was conducted according to the principles of the Declaration of Helsinki. All participants released their informed consent.

\subsection{EEG acquisition and processing}

EEG was acquired at bedside before the thrombolysis treatment and within $4.5 \mathrm{~h}$ from stroke onset by using Be Plus LTM amplifier @64 channels Wi-Fi (EBNeuro, Florence, Italy) and a wireless headset (EBNeuro, Florence, Italy) with $19 \mathrm{Ag} / \mathrm{AgCl}$ electrodes positioned according 10-20 system (Fp1, Fp2, F7, F3, Fz, F4, F8, T3, C3, Cz, C4, T4, T5, P3, $\mathrm{Pz}, \mathrm{P} 4, \mathrm{~T} 6, \mathrm{O} 1, \mathrm{O} 2)$. All electrode impedances were kept below $5 \mathrm{k} \Omega$, and sampling rate was set to $128 \mathrm{~Hz}$. The offline analysis was performed using scripts developed in MATLAB (MathWorks Inc., Natick, MA). The signals were digitally filtered with the $0.5-40 \mathrm{~Hz}$ 2nd order Butterworth bandpass filter. For each of 19 unipolar channels, power spectral density (PSD) was estimated on $120 \mathrm{~s}$ artifact-free segments by using Welch's periodogram [35], averaged on tracts of $10 \mathrm{~s}$ each, with applied Hann window. Subsequently, quantitative spectral parameters relative delta, theta, alpha, and beta power, as well as (delta+theta)/(alpha+beta) power ratio (DTABR) and delta/alpha power ratio (DAR), were calculated. The absolute 
power for each of spectral band (delta $1-4 \mathrm{~Hz}$; theta 4-8 Hz; alpha 8-13 Hz; beta $13-30 \mathrm{~Hz}$ ) was calculated for each channel, and then normalized with a total power across the 1$30 \mathrm{~Hz}$ range to obtain relative powers. In addition, also aforementioned DAR and DTABR were extracted. Relative power for each band, DAR, and DTABR parameters were averaged over all nineteen electrodes.

\subsection{Neuroimaging assessment}

All CT imaging (NECT, CTA, and CTP) was performed with 256-slice CT scanner (Brilliance iCT; Philips Medical Systems, Best, Netherlands). In particular, CTP acquisition protocol involved intravenous injection of $75 \mathrm{ml}$ of contrast medium, followed by a $40 \mathrm{ml}$ of saline bolus, both administered at an injection rate of $4 \mathrm{ml} / \mathrm{s}$. The exposure parameters adopted were $80 \mathrm{kVp}$ and 150-200 mAs. Three-dimensional axial acquisitions on a whole brain volume with a reconstruction of the slices set to $5 \mathrm{~mm}$ were performed. The acquisitions were carried out every $4 \mathrm{~s}$, resulting in a total scanning time of 60 s. CTP source image processing was performed, and CTP maps were calculated, as previously described $[2,16,32]$. Ischemic core and penumbra areas were identified by application of specific thresholds [36].

\subsection{Outcome measures}

We have measured the clinical outcome in terms of NIHSS on the 7th day or earlier in case of discharge (7-day NIHSS) and 12 months after the ischemic event (12-month NIHSS). The NIHSS, consisting of 11 items to assess the main neurological functions, is the most adopted tool in the actual medical practice to evaluate stroke-related neurologic impairment at admission and evaluate clinical evolution and final outcome [1]. In addition, functional outcome was measured by modified Rankin scale (mRS) 1 year after the stroke event [34]. The $\mathrm{mRS}$, an ordinal scale with 7 categories ranging from zero (no symptoms) to 6 (death), was the outcome measure: 0 - no symptoms at all; 1 -no significant disability despite symptoms, able to carry out all usual duties and activities; 2slight disability, unable to carry out all previous activities, but able to look after own affairs without assistance; 3 moderate disability, requiring some help, but able to walk without assistance; 4 -moderately severe disability, unable to walk and attend to bodily needs without assistance; 5severe disability, bedridden, incontinent, and requiring constant nursing care and attention; 6- dead. Good outcome class was defined with $\mathrm{mRS} \leq 2$, while bad outcome class with $\mathrm{mRS}>3$.

Morphological outcome was evaluated in terms of final ischemic volume, which was identified by segmentation on follow-up NECT by using a seed-based region growing algorithm implemented in Matlab (MathWorks Inc., Natick, MA) and additionally manually outlined by two trained neurologists.

\subsection{Statistical analysis}

The Spearman correlation was used to determine the degree of correlation between the EEG parameters and outcome measures (i.e., 7-day and 12-month NIHSS, final infarct volume). Statistical significance was set at $p<0.05$. In testing the significance of correlation coefficients, as used for similar purposes in previous EEG studies [13, 14], the stringent Bonferroni correction for multiple comparisons was applied to maintain the total type I error rate at a sufficiently low level [18]. Univariate binary logistic regression was performed to assess the association between $\mathrm{mRS} \leq 2$ at 12 -month and EEG parameters in their natural logarithm (ln).

\section{Results}

Demographic, clinical, and neuroimaging data are summarized in Table 1. Mean age was $75.8 \pm 12.1$ years; median NIHSS at admission was 10 (range 3-23). Median time between onset of symptoms and hyper-acute EEG recording was 196 min (range 81-267 min). CT assessment at admission showed median ASPECT score of 9.5 (range 7-10).

Median NIHSS at 7-day and 12-month were 4 (range 0-42) and 2 (range $0-42$ ), respectively. Eleven patients (55\%) presented $\mathrm{mRS} \leq 2$ at 12 months. Median final ischemic volume calculated on follow-up NECT was $4.6 \mathrm{ml}(0-116.0 \mathrm{ml})$. No sICH was observed.

Relative power of theta, delta, alpha and beta EEG bands, DAR, and DTABR calculated ratios, as well as correlation with 7-day NIHSS, 12-month NIHSS, 12-month mRS, and final ischemic volume, are reported in Table 2.

Seven-day NIHSS as well as 12-month NIHSS correlated significantly with alpha (rho $=-81, p=0.001$, and rho $=-$ $0.78, p=0.001$, respectively), delta (rho $=0.80, p=0.001$, and rho $=0.73, p=0.003$, respectively), DAR (rho $=0.76$, $p=0.002$ and rho $=0.74, p=0.003$; respectively), and DTABR (rho $=0.75, p=0.002$, and rho $=0.73, p=0.003$; respectively). The same EEG parameters correlated also with NIHSS at admission (Table 2). In Fig. 1, NIHSS measured in the various evaluation moments was plotted against DAR parameter calculated at admission.

A good outcome in terms of $\mathrm{mRS} \leq 2$ at 12 months was associated with DAR parameter $(p=0.008)$. The final infarct volume correlated with all EEG parameters, except theta and beta power. In particular, a strong direct correlation was observed for relative delta power, DAR, and DTABR (rho $=$ $0.75, p<0.001 ;$ rho $=0.78, p<0.001 ;$ rho $=0.62, p=0.005$, respectively), as well as inverse for relative alpha power (rho $=$ $-0.70, p<0.001)$. 
Table 1 Participants' demographics and clinical and radiological characteristics

\begin{tabular}{|c|c|}
\hline Personal characteristics & $n=20$ \\
\hline Age (years) & $75.8 \pm 12.1$ \\
\hline Sex F/M & $12 / 8$ \\
\hline BMI & $24.5 \pm 2.8$ \\
\hline $\begin{array}{l}\text { Symptom onset-EEG } \\
\text { (min) }\end{array}$ & $196(81-267)$ \\
\hline ASPECTS & $9.5(7-10)$ \\
\hline NIHSS at admission & $10(3-23)$ \\
\hline NIHSS 7-day & $4(0-42)$ \\
\hline NIHSS 12-month & $2(0-42)$ \\
\hline mRS $0-2 n(\%)$ anamnestic & $18(90 \%)$ \\
\hline mRS $0-2 n(\%)$ discharge & $8(40 \%)$ \\
\hline mRS 0-2 n(\%) 12-month & $11(55 \%)$ \\
\hline Lesion side of the lesion L/R (n) & $12 / 8$ \\
\hline \multicolumn{2}{|l|}{ Bamford stroke subtypes } \\
\hline TACI & $6(30 \%)$ \\
\hline PACI & $13(65 \%)$ \\
\hline LACI & $1(5 \%)$ \\
\hline \multicolumn{2}{|l|}{ TOAST classification } \\
\hline Atherothrombotic & $4(20 \%)$ \\
\hline Lacunar & $1(5 \%)$ \\
\hline Cardioembolic & $8(40 \%)$ \\
\hline Cryptogenic & $6(30 \%)$ \\
\hline Other cause & $1(5 \%)$ \\
\hline \multicolumn{2}{|l|}{ CTP parameters } \\
\hline Total hypoperfused tissue [ml] & $61.0(2.0-238.0)$ \\
\hline Core $(\mathrm{ml})$ & $5.5(0-86.0)$ \\
\hline Mismatch & $0.89(0.32-1.0)$ \\
\hline Final infarct volume(ml) & $4.6(0-116.5)$ \\
\hline $\operatorname{HTN}(n(\%))$ & $14(70 \%)$ \\
\hline $\operatorname{DM}(n(\%))$ & $12(60 \%)$ \\
\hline Dyslipidemia $(n(\%))$ & $15(75 \%)$ \\
\hline $\operatorname{AF}(n(\%))$ & $8(40 \%)$ \\
\hline $\operatorname{ICM}(n(\%))$ & $4(20 \%)$ \\
\hline
\end{tabular}

Notes: participants' reported age (year), sex (n), BMI (body mass index), Symptom onset-EEG assessment (min), ASPECTS, NIHSS at admission, NIHSS 7-day, NIHSS 12-month, anamnestic mRS $<3(\%)$, $\mathrm{mRS}$ at discharge $<3(\%), \mathrm{mRS}$ at 12 months $<3(\%)$, lesion side $(n)$, Bamford stroke subtypes (\%) (total anterior circulation infarct, TACI; partial anterior circulation infarct, PACI; lacunar stroke, LACI), TOAST classification (\%), CT perfusion parameters ( $\mathrm{ml})$, final infarct volume on follow-up $\mathrm{CT}(\mathrm{ml})$, and history of hypertension (HTN, \%), diabetes (DM, \%), dyslipidemia (\%), atrial fibrillation (AF, \%), ischemic cardiomyopathy (ICM, $\%)$

\section{Discussion}

The study of the new early prognostic factors that modulate the stroke outcome may support a personalized therapeutic intervention to improve patients' recovery. Neurophysiological biomarkers seem increasingly applicable to predict outcome $[6,12]$ owing to the growing evidence of neurovascular coupling in acute ischemic stroke [29, 32]. Early pre-treatment EEG parameters in the hyper-acute phase ( $<4.5 \mathrm{~h}$ from symptom onset) have not yet been studied as predictive factors of the short- and long-term outcome in thrombolysis-treated stroke patients.

The main finding of this study is that early EEG parameters assessed bedside by wireless devices may contribute to the prediction of neurological deficit, functional disability, and morphological lesion at discharge and at 12 months in thrombolysis-treated stroke patients.

In particular, 7-day and 12-month NIHSS outcomes were inversely related to relative alpha power and directly related to relative delta power as well as DAR and DTABR parameters. A good clinical outcome measured with $\mathrm{mRS} \leq 2$ at 1 year was strongly associated with DAR. Moreover, the final infarct volume was significantly associated with all considered EEG parameters, except theta and beta. In Fig. 2 are reported two different exemplificative cases of patients admitted to our stroke unit with an acute anterior ischemic stroke with different pre-thrombolysis EEG alterations resulting in two different functional outcomes and final infarct volume.

These findings support the hypothesis that these objective biomarkers, obtained by non-invasive and portable technique as wireless EEG, may add important short- and long-term prognostic information in hyper-acute thrombolysis-treated stroke patients. Indeed, early neurophysiological alterations measured by the identified EEG parameters were associated both to the clinical/functional and morphological outcomes. The clinical/functional outcome is highly related to the final extent of the ischemic infarct, although this is also dependent on lesion location $[5,19,23]$. A preserved alpha power with limited increase of delta power in hyper-acute pre-treatment phase is indicative of neuronal survival in the ischemic regions and consequently of a good prognosis after the reperfusion treatment.

The still arduous stroke outcome early prognosis may also be improved by taking these EEG pre-treatment markers into account to reduce the gap due to large inter-subject variability. Recently, a sub-acute EEG stroke study showed that outcome models including quantitative EEG parameters and other clinical/neuroimaging stroke outcome predictors were found to be superior to models without EEG data [6].

The sub-acute stroke studies reported significant functional and clinical predictive power of relative delta, alpha power, DAR, and DTABR EEG-related parameters [6, 12, 14, 30]. Finnigan et al. reported that sub-acute $(49 \pm 3 \mathrm{~h}$ post symptom onset) DAR ratio (DAR; $r=0.91, p<0.001$ ) and relative alpha power $(r=0.82, p<0.01)$ were significantly correlated with 30-day NIHSS score in thirteen ischemic stroke patients [14]. Sheorajpanday et al. found a significant correlation 
Table 2 EEG indices and their correlation with functional/morphological outcome

\begin{tabular}{|c|c|c|c|c|c|c|}
\hline \multirow{2}{*}{$\begin{array}{l}\text { EEG } \\
\text { parameter }\end{array}$} & \multirow[b]{2}{*}{$\begin{array}{l}\text { Median } \\
\text { (range) }\end{array}$} & \multicolumn{3}{|l|}{ NIHSS } & \multirow{2}{*}{$\begin{array}{l}\begin{array}{l}\text { Final infarct } \\
\text { volume }\end{array} \\
\begin{array}{l}\text { Spearman's } \rho \\
(p \text { value })\end{array}\end{array}$} & \multirow{2}{*}{$\begin{array}{l}\mathrm{mRS} \leq 2 \\
\begin{array}{l}\mathrm{OR}(95 \% \mathrm{CI}) \\
(p \text { value })\end{array}\end{array}$} \\
\hline & & $\begin{array}{l}\text { Spearman's } \rho \\
\text { ( } p \text { value) }\end{array}$ & & & & \\
\hline & Admission & Admission & 7-day & 12-month & $24-48 \mathrm{~h}$ & 12-month \\
\hline Delta & $\begin{array}{l}0.41 \\
(0.25-0.67)\end{array}$ & $\begin{array}{l}0.82 \\
(p<0.001)\end{array}$ & $\begin{array}{l}0.80 \\
(p=0.001)\end{array}$ & $\begin{array}{l}0.73 \\
(p=0.003)\end{array}$ & $\begin{array}{l}0.75 \\
(p<0.001)\end{array}$ & $\begin{array}{l}0.005(0.000-0.494) \\
(p=0.023)\end{array}$ \\
\hline Theta & $\begin{array}{l}0.21 \\
(0.09-0.33)\end{array}$ & $\begin{array}{l}0.09 \\
(p=0.738)\end{array}$ & $\begin{array}{l}0.10 \\
(p=0.737)\end{array}$ & $\begin{array}{l}0.14 \\
(p=0.638)\end{array}$ & $\begin{array}{l}-0.06 \\
(p=0.801)\end{array}$ & $\begin{array}{l}1.170(0.091-15.021) \\
(p=0.904)\end{array}$ \\
\hline Alpha & $\begin{array}{l}0.15 \\
(0.06-0.38)\end{array}$ & $\begin{array}{l}-0.87 \\
(p<0.001)\end{array}$ & $\begin{array}{l}-0.81 \\
(p=0.001)\end{array}$ & $\begin{array}{l}-0.78 \\
(p=0.001)\end{array}$ & $\begin{array}{l}-0.70 \\
(p<0.001)\end{array}$ & $\begin{array}{l}129.938(2931-5760.319) \\
(p=0.012)\end{array}$ \\
\hline Beta & $\begin{array}{l}0.13 \\
(0.05-0.21)\end{array}$ & $\begin{array}{l}-0.29 \\
(p=0.312)\end{array}$ & $\begin{array}{l}-0.21 \\
(p=0.460)\end{array}$ & $\begin{array}{l}-0.19 \\
(p=0.511)\end{array}$ & $\begin{array}{l}0.26 \\
(p=0.301)\end{array}$ & $\begin{array}{l}1.402(0.152-12.943) \\
(p=0.766)\end{array}$ \\
\hline DAR & $\begin{array}{l}3.26 \\
(1.24-7.35)\end{array}$ & $\begin{array}{l}0.86 \\
(p<0.001)\end{array}$ & $\begin{array}{l}0.76 \\
(p=0.002)\end{array}$ & $\begin{array}{l}0.74 \\
(p=0.003)\end{array}$ & $\begin{array}{l}0.78 \\
(p<0.001)\end{array}$ & $\begin{array}{l}0.023(0.001-0.380) \\
(p=0.008)\end{array}$ \\
\hline DTABR & $\begin{array}{l}2.45 \\
(1.13-4.66)\end{array}$ & $\begin{array}{l}0.85 \\
(p<0.001)\end{array}$ & $\begin{array}{l}0.75 \\
(p=0.002)\end{array}$ & $\begin{array}{l}0.73 \\
(p=0.003)\end{array}$ & $\begin{array}{l}0.62 \\
(p=0.005)\end{array}$ & $\begin{array}{l}0.018(0.001-0.493) \\
(p=0.017)\end{array}$ \\
\hline
\end{tabular}

Median (range) of calculated EEG spectral parameters. Correlation between extracted EEG spectral parameters and NIHSS (admission, 7-day, 12month) and final infarct volume at follow-up NECT $(24-48 \mathrm{~h})$; logistic regression for good outcome (mRS 12 -month $\leq 2)$ using the EEG variables transformed into the natural logarithm.

Note. Relative Delta, Theta, Alpha and Beta power, DAR delta/alpha power ratio; DTABR (delta + theta)/(alpha + beta) power ratio; NIHSS National Institutes of Health Stroke Scale score; $m R S$ modified Rankin scale; $\rho$ Spearman's rho correlation coefficient; $O R$ odds ratio; $C I$ confidence interval; statistically significant correlations are highlighted in italics.

between EEG (acquired from 3 to $168 \mathrm{~h}$ since symptom onset, median $24 \mathrm{~h}$ ) parameters and $\mathrm{mRS}$ at 6 month in 75 patients with a first ever stroke $(0.42, p<0.0005$ for the pairwise derived Brain Symmetry Index (pdBSI) and $0.43, p<0.0005$ for DTABR) [30]. The same study observed a significant correlation between pdBSI and NIHSS 7-day and final infarct volume but not between other EEG parameters, in 21 patients with an early EEG registration in the timespan between 3 and $6 \mathrm{~h}$ since stroke onset [30]. Bentes et al. observed that delta, alpha, beta relative powers, and DTABR predicted outcome in
Fig. 1 Neurological deficit in terms of NIHSS measured in the various time moments (admission, 7-day, 12-month) plotted against delta-to-alpha ratio (DAR) calculated from EEG tracings registered at admission. The correlation coefficients observed between DAR and NIHSS were rho $=0.86(p<0.001)$, rho $=0.76(p=0.002)$, and rho $=$ $0.74(p=0.003)$ for NIHSS evaluated at admission, 7-day, and 12month, respectively
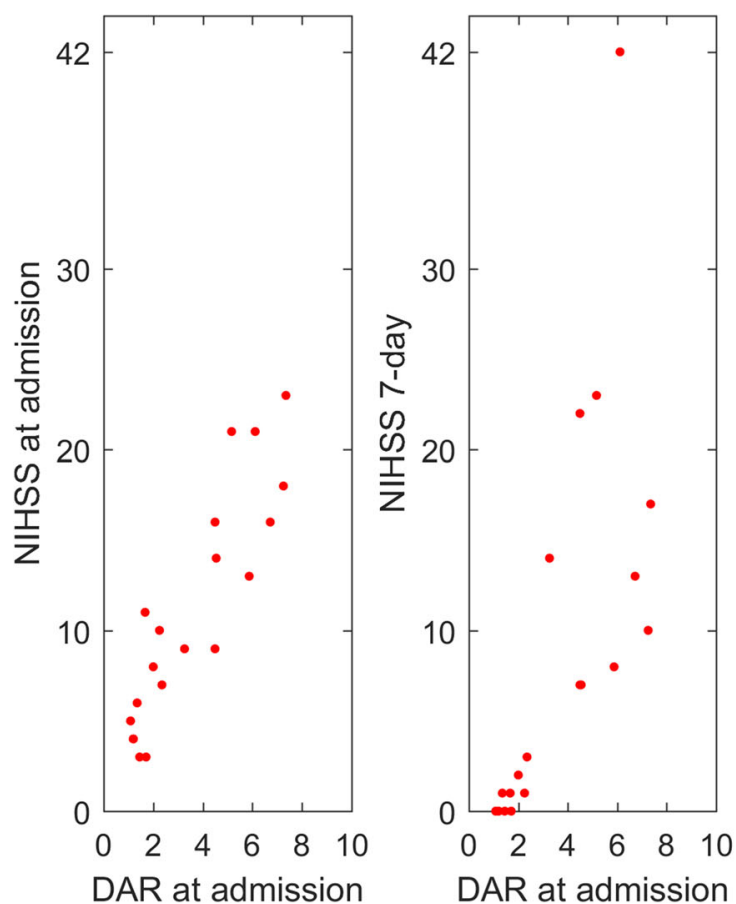

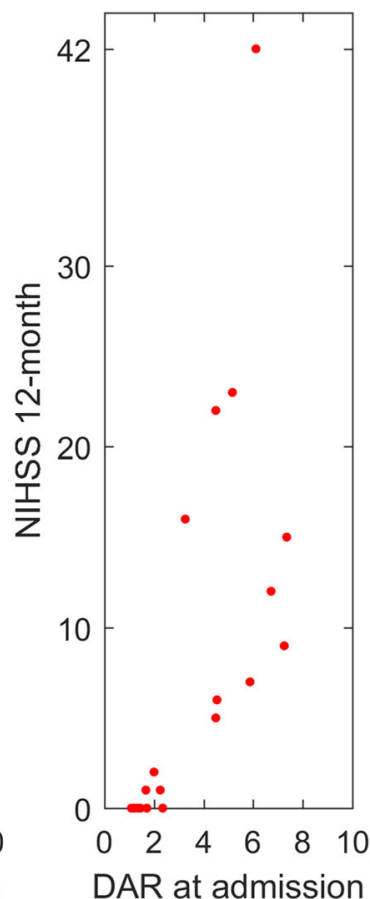


a
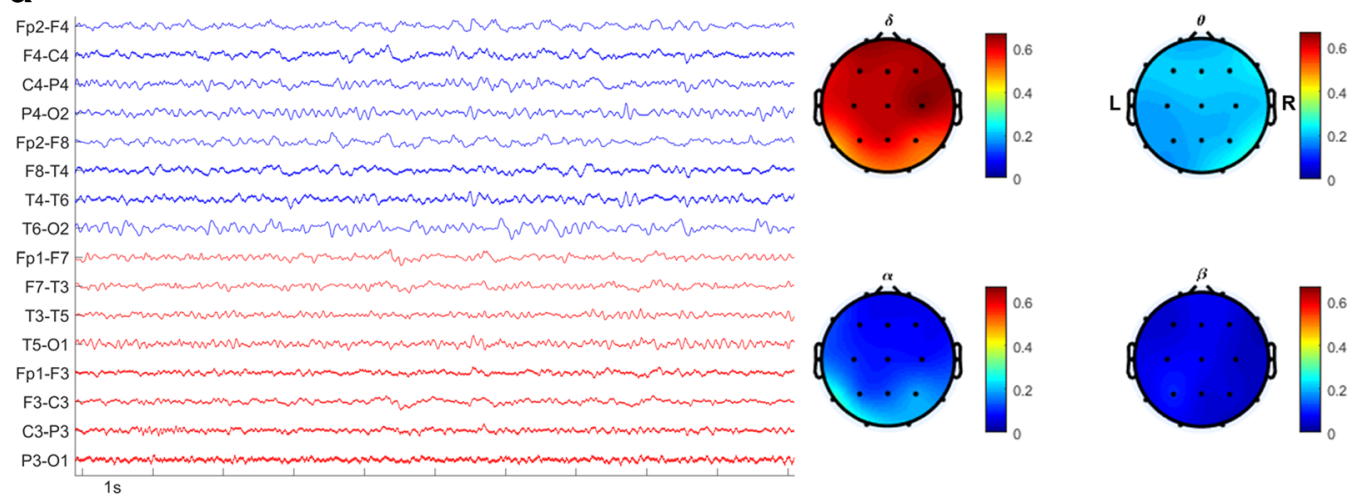

\section{b}
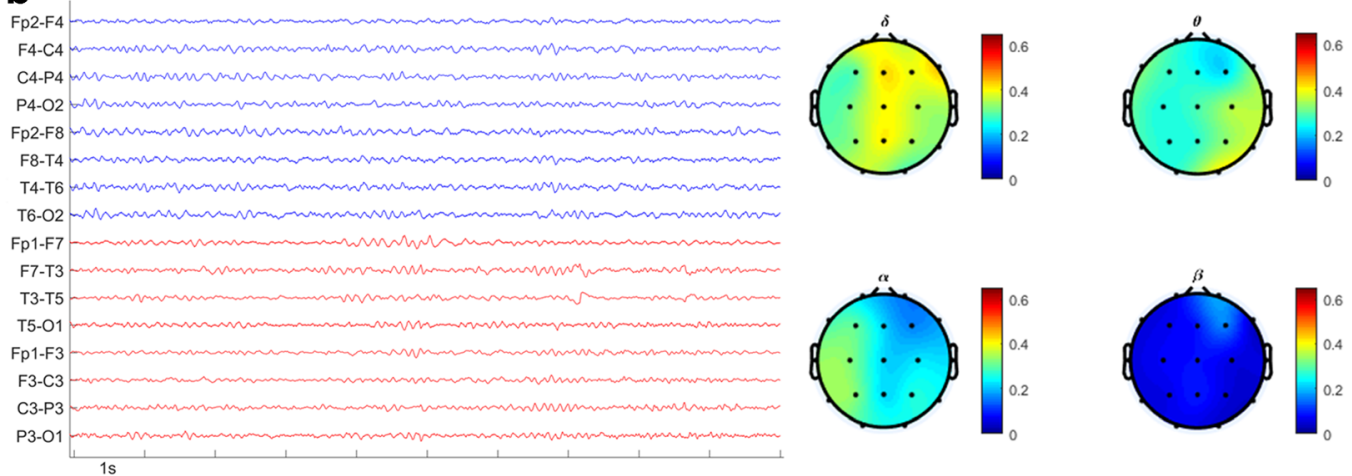
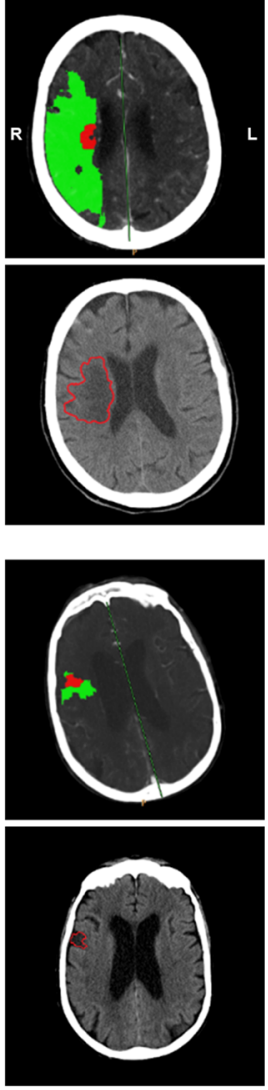

morphological outcomes. Baseline features: male, 87 years, premorbid $\mathrm{mRS}=1$, NIHSS at admission $=6$, PACI, cardioembolic etiology, ASPECTS $=10$, right distal middle cerebral artery occlusion, CTP total hypoperfused volume $=8.5 \mathrm{ml}$, CTP core volume $=2.8 \mathrm{ml}$, relative spectral powers delta $=0.33$, theta $=0.29$, alpha $=0.23$, beta $=0.15$, DAR $=$ 1.43 , DTABR $=1.63$. Clinical and morphological outcomes: NIHSS 7day $=1$, NIHSS 12 -month $=0, \mathrm{mRS}$ at discharge $=1,12$-month $\mathrm{mRS}=1$, final infarct volume $=3.6 \mathrm{ml}$. From left to right: 16 -channel longitudinal bipolar montage of EEG raw data, EEG spectral power topographic maps, CTP core-penumbra summary map with estimated necrotic core area (MTT higher than $145 \%$ of the contralateral healthy area and CBV < $2.0 \mathrm{~mL} / 100 \mathrm{~g}$ ), and salvageable penumbra area (MTT higher than $145 \%$ of the contralateral healthy area and CBV $>2.0 \mathrm{~mL} / 100 \mathrm{~g}$ ), highlighted in red and green, respectively, follow-up NECT with delineated final infarct lesion

to guiding treatment and rehabilitation strategies in the earliest phase of ischemic event in the era of personalized medicine.

Portable wireless device enabled our study to adopt early EEG recording, thus avoiding to delay the treatment and compromise the patient management. The wireless EEG device digitized analog EEG electrical signals at a point close to the electrodes and subsequently transmitted EEG signals via $\mathrm{Wi}-\mathrm{Fi}$ protocol to a base station. This allowed to minimize movement of electrode wires, a major source of electromagnetic interference [33] and electrode displacement that dramatically degrades EEG signal quality. Our study also showed that adequate acceptable quality of EEG data can be obtained in such adverse recording conditions 
as stroke-emergency setting. The state-of-the-art portable technologies may overcome most of EEG application inhibiting factors occurring in emergency settings such as stroke units $[9,10]$.

Perfusion neuroimaging, such as MRI and CTP techniques, are crucial in ischemic stroke assessment and patient selection due the identification of ischemic core and salvageable hypoperfused penumbra $[15,16,21,26]$ However, these techniques are not feasible tools to monitor brain ischemia evolution in the acute phase. Brain oscillatory activity changes occurring in acute ischemic stroke are related to neurophysiological changes (measured by EEG) in the cerebral tissue during hypoperfusion as manifestation of neurovascular coupling [29, 32]. Hence, EEG in the hyperacute phase could be a feasible instrument of realtime functional monitoring, considering its high correlation also with neurological deficit at admission [3], as well the correlation in the later acute phases [14], can be potentially considered in the future as an objective surrogate parameter for functional monitoring.

This study has some limitations. Owing to non-ideal bedside acquisition conditions in the first minutes of hospitalization in an emergency setting, artifacts related to the initial medical assessments and nursing care could not be avoided. In addition, the results were obtained from a limited sample of a single Stroke Unit and should be confirmed in a larger study. Due to the limited sample, we performed only univariate analysis; further studies on broader sample are needed to identify the strongest EEG predictive factor. The aim of this preliminary study was to assess the informativeness of EEG objective instrumental parameters in the pre-treatment stage. Not only may EEG at admission deliver a static picture as does neuroimaging, but it may also offer a continuous monitoring of acute neuro-physiological changes over time, thus updating the information on patients' clinical condition and prognosis. Despite the above-mentioned limitations, our cohort was a homogenous and representative sample of hyper-acute (median time from symptom onset to EEG assessment $=196 \mathrm{~min}$ ) anterior circulation stroke patients, with a median NIHSS score of 10 (3-23) and a mean age of $75.85 \pm 12.1$ years.

\section{Conclusions}

The results of this hyper-acute wireless EEG study showed that relative delta power, relative alpha power, DAR, and DTABR ratios correlate with neurological deficit and morphological lesion at discharge and at 12 months in thrombolysis-treated stroke patients. These neurophysiological biomarkers, obtained by non-invasive and portable technique as wireless EEG in the early pre-treatment phase, may contribute as objective parameters to the short- and long-term outcome prediction, which is pivotal to better establish the treatment strategies. The biomarkers may provide a bedside real-time picture of the probable response to thrombolytic therapy and may be potentially considered in the future as an objective surrogate parameter for longitudinal monitoring.

Acknowledgments The authors would like to thank Matteo di Franza for editorial assistance and English proof-reading.

Funding Open access funding provided by Università degli Studi di Trieste within the CRUI-CARE Agreement.

\section{Compliance with ethical standards}

Conflict of interests The authors declared no potential conflicts of interest with respect to the research, authorship, and/or publication of this article. Figures are original and not previously published.

Open Access This article is licensed under a Creative Commons Attribution 4.0 International License, which permits use, sharing, adaptation, distribution and reproduction in any medium or format, as long as you give appropriate credit to the original author(s) and the source, provide a link to the Creative Commons licence, and indicate if changes were made. The images or other third party material in this article are included in the article's Creative Commons licence, unless indicated otherwise in a credit line to the material. If material is not included in the article's Creative Commons licence and your intended use is not permitted by statutory regulation or exceeds the permitted use, you will need to obtain permission directly from the copyright holder. To view a copy of this licence, visit http://creativecommons.org/licenses/by/4.0/.

\section{References}

1. Adams HPJ, Davis PH, Leira EC et al (1999) Baseline NIH Stroke Scale score strongly predicts outcome after stroke: a report of the Trial of Org 10172 in Acute Stroke Treatment (TOAST). Neurology 53:126-131. https://doi.org/10.1212/wnl.53.1.126

2. Ajčević M, Furlanis G, Buoite Stella A et al (2020a) A CT perfusion based model predicts outcome in wake-up stroke patients treated with recombinant tissue plasminogen activator. Physiol Meas 41:075011. https://doi.org/10.1088/1361-6579/ab9c70

3. Ajčević M, Furlanis G, Stragapede L, Ridolfi M, Caruso P, Naccarato M, Accardo A, Manganotti P (2020b) Brain oscillatory activity and neurological deficit in hyper-acute ischemic stroke: correlation of EEG changes with NIHSS. In: Henriques J, Neves N, de Carvalho P (eds) XV Mediterranean Conference on Medical and Biological Engineering and Computing - MEDICON 2019. Springer International Publishing, Cham, pp 133-141. https://doi. org/10.1007/978-3-030-31635-8 16

4. Albers GW, Marks MP, Kemp S, Christensen S, Tsai JP, OrtegaGutierrez S, McTaggart R, Torbey MT, Kim-Tenser M, LeslieMazwi T, Sarraj A, Kasner SE, Ansari SA, Yeatts SD, Hamilton S, Mlynash M, Heit JJ, Zaharchuk G, Kim S, Carrozzella J, Palesch YY, Demchuk AM, Bammer R, Lavori PW, Broderick JP, Lansberg MG, DEFUSE 3 Investigators (2018) Thrombectomy for stroke at 6 to 16 hours with selection by perfusion imaging. $\mathrm{N}$ Engl J Med 378:708-718. https://doi.org/10.1056/ NEJMoa1713973

5. Bagher-Ebadian H, Jafari-Khouzani K, Mitsias PD, Lu M, Soltanian-Zadeh H, Chopp M, Ewing JR (2011) Predicting final extent of ischemic infarction using artificial neural network analysis of multi-parametric MRI in patients with stroke. PLoS One 6: e22626. https://doi.org/10.1371/journal.pone.0022626 
6. Bentes C, Peralta AR, Viana P, Martins H, Morgado C, Casimiro C, Franco AC, Fonseca AC, Geraldes R, Canhão P, Pinho e Melo T, Paiva T, Ferro JM (2018) Quantitative EEG and functional outcome following acute ischemic stroke. Clin Neurophysiol 129: 1680-1687. https://doi.org/10.1016/j.clinph.2018.05.021

7. Campbell BCV, Ma H, Ringleb PA et al (2019) Extending thrombolysis to $4.5-9 \mathrm{~h}$ and wake-up stroke using perfusion imaging: a systematic review and meta-analysis of individual patient data. Lancet, London. https://doi.org/10.1016/S0140-6736(19)31053-0

8. Caruso P, Naccarato M, Furlanis G, Ajčević M, Stragapede L, Ridolfi M, Polverino P, Ukmar M, Manganotti P (2018) Wake-up stroke and $\mathrm{CT}$ perfusion: effectiveness and safety of reperfusion therapy. Neurol Sci 39:1705-1712. https://doi.org/10.1007/ s10072-018-3486-Z

9. David Hairston W, Whitaker KW, Ries AJ, Vettel JM, Cortney Bradford J, Kerick SE, McDowell K (2014) Usability of four commercially-oriented EEG systems. J Neural Eng 11:46018. https://doi.org/10.1088/1741-2560/11/4/046018

10. Debener S, Minow F, Emkes R, Gandras K, de Vos M (2012) How about taking a low-cost, small, and wireless EEG for a walk? Psychophysiology 49:1617-1621. https://doi.org/10.1111/j.14698986.2012.01471.x

11. Demchuk AM, Tanne D, Hill MD, Kasner SE, Hanson S, Grond M, Levine SR, The Multicentre tPA Stroke Survey Group (2001) Predictors of good outcome after intravenous tPA for acute ischemic stroke. Neurology 57:474-480. https://doi.org/10.1212/wnl.57. 3.474

12. Finnigan S, van Putten MJAM (2013) EEG in ischaemic stroke: quantitative EEG can uniquely inform (sub-)acute prognoses and clinical management. Clin Neurophysiol 124:10-19. https://doi. org/10.1016/j.clinph.2012.07.003

13. Finnigan SP, Rose SE, Walsh M, Griffin M, Janke AL, McMahon KL, Gillies R, Strudwick MW, Pettigrew CM, Semple J, Brown J, Brown P, Chalk JB (2004) Correlation of quantitative EEG in acute ischemic stroke with 30-day NIHSS score: comparison with diffusion and perfusion MRI. Stroke 35:899-903. https://doi.org/10. 1161/01.STR.0000122622.73916.d2

14. Finnigan SP, Walsh M, Rose SE, Chalk JB (2007) Quantitative EEG indices of sub-acute ischaemic stroke correlate with clinical outcomes. Clin Neurophysiol 118:2525-2532. https://doi.org/10. 1016/j.clinph.2007.07.021

15. Furlanis G, Ajcevic M, Buoite Stella A et al (2020) Wake-up stroke: thrombolysis reduces ischemic lesion volume and neurological deficit. J Neurol 267:666-673. https://doi.org/10.1007/s00415-01909603-7

16. Furlanis G, Ajcevic M, Stragapede L et al (2018) Ischemic volume and neurological deficit: correlation of computed tomography perfusion with the National Institutes of Health stroke scale score in acute ischemic stroke. J Stroke Cerebrovasc Dis 27:2200-2207. https://doi.org/10.1016/j.jstrokecerebrovasdis.2018.04.003

17. Hacke W, Kaste M, Bluhmki E, Brozman M, Dávalos A, Guidetti D, Larrue V, Lees KR, Medeghri Z, Machnig T, Schneider D, von Kummer R, Wahlgren N, Toni D, ECASS Investigators (2008) Thrombolysis with alteplase 3 to 4.5 hours after acute ischemic stroke. N Engl J Med 359:1317-1329. https://doi.org/10.1056/ NEJMoa0804656

18. Howell D (1997) Statistical methods for psychology, 4th edn. Belmont, CA

19. Jacobs MA, Mitsias P, Soltanian-Zadeh H, Santhakumar S, Ghanei A, Hammond R, Peck DJ, Chopp M, Patel S (2001) Multiparametric MRI tissue characterization in clinical stroke with correlation to clinical outcome: part 2. Stroke 32:950-957. https:// doi.org/10.1161/01.str.32.4.950

20. Ma H, Campbell BCV, Parsons MW, Churilov L, Levi CR, Hsu C, Kleinig TJ, Wijeratne T, Curtze S, Dewey HM, Miteff F, Tsai CH, Lee JT, Phan TG, Mahant N, Sun MC, Krause M, Sturm J, Grimley
R, Chen CH, Hu CJ, Wong AA, Field D, Sun Y, Barber PA, Sabet A, Jannes J, Jeng JS, Clissold B, Markus R, Lin CH, Lien LM, Bladin CF, Christensen S, Yassi N, Sharma G, Bivard A, Desmond PM, Yan B, Mitchell PJ, Thijs V, Carey L, Meretoja A, Davis SM, Donnan GA, EXTEND Investigators (2019) Thrombolysis guided by perfusion imaging up to 9 hours after onset of stroke. N Engl J Med 380:1795-1803. https://doi.org/10.1056/ NEJMoa1813046

21. Manganotti P, Furlanis G, Ajčević M, Polverino P, Caruso P, Ridolfi M, Pozzi-Mucelli RA, Cova MA, Naccarato M (2019) CT perfusion and EEG patterns in patients with acute isolated aphasia in seizure-related stroke mimics. Seizure - Eur J Epilepsy 71:110 115. https://doi.org/10.1016/j.seizure.2019.07.005

22. McDermott M, Skolarus LE, Burke JF (2019) A systematic review and meta-analysis of interventions to increase stroke thrombolysis. BMC Neurol 19:86. https://doi.org/10.1186/s12883-019-1298-2

23. Mitsias PD, Jacobs MA, Hammoud R, Pasnoor M, Santhakumar S, Papamitsakis NIH, Soltanian-Zadeh H, Lu M, Chopp M, Patel SC (2002) Multiparametric MRI ISODATA ischemic lesion analysis: correlation with the clinical neurological deficit and singleparameter MRI techniques. Stroke 33:2839-2844. https://doi.org/ 10.1161/01.str.0000043072.76353.7c

24. National Institute of Neurological Disorders and Stroke rt-PA Stroke Study Group (1997) Generalized efficacy of t-PA for acute stroke. Subgroup analysis of the NINDS t-PA Stroke Trial. Stroke 28:2119-2125. https://doi.org/10.1161/01.str.28.11.2119

25. Nogueira RG, Jadhav AP, Haussen DC, Bonafe A, Budzik RF, Bhuva P, Yavagal DR, Ribo M, Cognard C, Hanel RA, Sila CA, Hassan AE, Millan M, Levy EI, Mitchell P, Chen M, English JD, Shah QA, Silver FL, Pereira VM, Mehta BP, Baxter BW, Abraham MG, Cardona P, Veznedaroglu E, Hellinger FR, Feng L, Kirmani JF, Lopes DK, Jankowitz BT, Frankel MR, Costalat V, Vora NA, Yoo AJ, Malik AM, Furlan AJ, Rubiera M, Aghaebrahim A, Olivot JM, Tekle WG, Shields R, Graves T, Lewis RJ, Smith WS, Liebeskind DS, Saver JL, Jovin TG, DAWN Trial Investigators (2018) Thrombectomy 6 to 24 hours after stroke with a mismatch between deficit and infarct. N Engl J Med 378:11-21. https://doi. org/10.1056/NEJMoa1706442

26. Peisker T, Koznar B, Stetkarova I, Widimsky P (2017) Acute stroke therapy: a review. Trends Cardiovasc Med 27:59-66. https://doi. org/10.1016/j.tcm.2016.06.009

27. Powers WJ, Rabinstein AA, Ackerson T et al (2019) Guidelines for the Early Management of Patients With Acute Ischemic Stroke: 2019 update to the 2018 Guidelines for the Early Management of Acute Ischemic Stroke: a guideline for healthcare professionals from the American Heart Association/American Stroke. Stroke 50:e344-e418

28. Reid JM, Gubitz GJ, Dai D, Kydd D, Eskes G, Reidy Y, Christian C, Counsell CE, Dennis M, Phillips SJ (2010) Predicting functional outcome after stroke by modelling baseline clinical and CT variables. Age Ageing 39:360-366. https://doi.org/10.1093/ageing/ afq027

29. Rossini PM, Altamura C, Ferretti A et al (2004) Does cerebrovascular disease affect the coupling between neuronal activity and local haemodynamics? Brain 127:99-110. https://doi.org/10.1093/brain/ awh012

30. Sheorajpanday RVA, Nagels G, Weeren AJTM, van Putten MJAM, de Deyn PP (2011) Quantitative EEG in ischemic stroke: correlation with functional status after 6 months. Clin Neurophysiol 122:874-883. https://doi.org/10.1016/j.clinph.2010.07.028

31. Stinear C (2010) Prediction of recovery of motor function after stroke. Lancet Neurol 9:1228-1232. https://doi.org/10.1016/ S1474-4422(10)70247-7

32. Stragapede L, Furlanis G, Ajcevic M et al (2019) Brain oscillatory activity and CT perfusion in hyper-acute ischemic stroke. J Clin 
Neurosci 69(19):184-189. https://doi.org/10.1016/j.jocn.2019.07. 068

33. Usakli AB (2010) Improvement of EEG signal acquisition: an electrical aspect for state of the art of front end. Comput Intell Neurosci 2010:630649-630647. https://doi.org/10.1155/2010/630649

34. van Swieten JC, Koudstaal PJ, Visser MC, Schouten HJ, van Gijn J (1988) Interobserver agreement for the assessment of handicap in stroke patients. Stroke 19:604-607. https://doi.org/10.1161/01.str. 19.5.604

35. Welch P (1967) The use of fast Fourier transform for the estimation of power spectra: a method based on time averaging over short, modified periodograms. IEEE Trans Audio Electroacoust 15:7073. https://doi.org/10.1109/TAU.1967.1161901

36. Wintermark M, Flanders AE, Velthuis B, Meuli R, van Leeuwen M, Goldsher D, Pineda C, Serena J, Schaaf I, Waaijer A, Anderson J, Nesbit G, Gabriely I, Medina V, Quiles A, Pohlman S, Quist M, Schnyder P, Bogousslavsky J, Dillon WP, Pedraza S (2006) Perfusion-CT assessment of infarct core and penumbra: receiver operating characteristic curve analysis in 130 patients suspected of acute hemispheric stroke. Stroke 37:979-985. https://doi.org/10. 1161/01.STR.0000209238.61459.39

37. Wolf M, Ebert DA, Chatzikonstantinou A (2017) The use of routine EEG in acute ischemic stroke patients without seizures: generalized but not focal EEG pathology is associated with clinical deterioration. Int J Neurosci 127:421-426. https://doi.org/10.1080/ 00207454.2016.1189913

Publisher's note Springer Nature remains neutral with regard to jurisdictional claims in published maps and institutional affiliations.

Miloš Ajčević , MEng, $\mathrm{PhD}$, is senior research associate at Biomedical Engineering group, University of Trieste, Italy. He received his MSc-Eng degree (summa cum laude) in Electronic Engineering and the $\mathrm{PhD}$ degree in Information Engineering (curriculum Biomedical Engineering) at the University of Trieste. He was a post-doctoral fellow at the Neurofarba Department of University of Florence. His research activities concern biomedical signal and image processing and analysis, with focus on neurophysiological signals and neuroimaging.

Giovanni Furlanis, MD, is research associate and neurologist at the Clinical Unit of Neurology, Cattinara University Hospital ASUGI, Trieste, Italy. He graduated at the school of medicine of the University of Trieste in 2013, where he received his specialization in Neurology in 2020 . He is the author of several papers on stroke treatment and advanced neuroimaging and neurophysiology, involving an interdisciplinary approach.

Marcello Naccarato, MD PhD, is a neurologist, supervisor of the Stroke Unit of Cattinara University Hospital ASUGI, Trieste, Italy. He graduated at the University of Padua School of Medicine in 1999, where he also received his specialization in Neurology in 2004 and the PhD in
Neuroscience in 2009. His expertise includes stroke management and therapy and advanced neuroimaging techniques. As a researcher, he also attended the University of Cambridge in 2003 and the University of Edinburgh in 2009.

Aleksandar Miladinović, MEng, MSc, is currently a $\mathrm{PhD}$ candidate in Biomedical Engineering at the University of Trieste. He graduated in Computer Science in 2012 in Belgrade, Serbia and in Cognitive Science in 2017 in Vienna, Austria, and Ljubljana, Slovenia. He also attended the Institute of Computer Technology at the Vienna University of Technology. His main research interest focuses on Brain-Computer Interfaces (BCI) for neurorehabilitation and EEG applications and analysis in Motor Mental Imagery.

Alex Buoite Stella, $\mathrm{PhD}$, is a physiologist and postdoctoral researcher at the Department of Medicine, Surgery and Health Sciences of the University of Trieste, Italy. He received his MSc in Applied Kinesiology at the University of Primorska (SLO) in 2012, and his $\mathrm{PhD}$ in Biomedical Sciences and Biotechnologies at the University of Udine in 2017. His research includes an integrative and translational approach to clinical physiology applied to neurologic conditions.

Paola Caruso, MD, is a neurologist at the Stroke Unit of Cattinara University Hospital ASUGI, Trieste, Italy. She graduated at the University of Trieste School of Medicine in 2009, and received her specialization in Neurology in 2015. She is an expert on cerebrovascular diseases and in particular in transcranial Doppler ultrasound.

Tommaso Cillotto, MD, is a visiting physician at the Stroke Unit of Cattinara University Hospital ASUGI, Trieste, Italy. He graduated at the University of Trieste School of Medicine in 2019. His main interest is in cerebrovascular diseases and in particular in wake-up stroke treatment and management.

Agostino Accardo, MEng, is associate professor of Biomedical Engineering and head of Biomedical Engineering group at the University of Trieste, Italy. He received his degree (summa cum laude) in Electronic Engineering from the University of Trieste, in 1979. Currently, he is the Dean of the Master degree course in Clinical Engineering and the Director of post-master degree courses in Clinical Engineering at the University of Trieste. His main research interest focuses on physiological signal processing by means of linear and non-linear methods.

Paolo Manganotti , MD, $\mathrm{PhD}$, neurologist and physiatrist. He is a full professor of Neurology at the University of Trieste and director of the Clinical Unit of Neurology at Cattinara University Hospital ASUGI, Trieste, Italy. He received his graduation in medicine and specializations at the University of Verona. He is author of numerous high-impact publications on clinical and basic neurophysiology, including the use and validation of advanced techniques for EEG, TMS, and fMRI. 